\title{
Calcite deposition in karst waters is promoted by leaf litter breakdown and vice versa
}

\author{
Marko Miliša ${ }^{1 *}$, Anita Belančić ${ }^{2}$, Renata Matoničkin Kepčija ${ }^{1}$, Mirela Sertić-Perić ${ }^{1}$, \\ Ana Ostojić ${ }^{1}$ and Ivan Habdija ${ }^{1}$ \\ ${ }^{1}$ Department of Zoology, Division of Biology, Faculty of Science, University of Zagreb, Rooseveltov trg 6, 10000 Zagreb, Croatia \\ 2 Plitvice Lakes National Park, Scientific Research Center "Ivo Pevalek", 53231 Plitvice Lakes, Croatia
}

Received 7 July 2010; Accepted 7 September 2010

\begin{abstract}
Plant litter breakdown, an important process for energy and matter flows in freshwater ecosystems, has been extensively studied except in the karst (and calcite depositing) habitats. The aim of this paper was to answer three questions regarding the breakdown of leaf litter in calcite depositing environment: (i) Does leaf decomposition hinder calcite deposition and vice versa?; (ii) What role do other environmental factors play?; and (iii) How long does leaf litter persist in these habitats? Leaves of beech (Fagus sylvatica) and butterbur (Petasites hybridus) were exposed for 8 weeks in 8 microhabitats: 2 calcite deposition rates $\times 2$ flow velocities $\times 2$ seasons. A linear model was better at predicting leaf litter persistence but only for the period after the extreme loss of leaf mass occurring during the initial leaching of highly hydrosoluble compounds in the first week (11.6\% of beech and $54.2 \%$ of butterbur regardless of the studied environmental factors). Higher flow velocity and calcite deposition rates stimulated the breakdown of both leaf species. During summer, breakdown was accelerated for butterbur leaves only. Since breakdown rates of both litter types were faster at high calcite depositing sites, it can be concluded that the breakdown process is not hindered by calcite deposition in general. The amount of deposited calcite per gram of leaf litter increased linearly over time (after the first week of exposure) on both leaf species. More calcite was deposited on the fast-decomposing butterbur leaves than on beech leaves.
\end{abstract}

Key words: Tufa / travertine / beech / butterbur / Croatia

\section{Introduction}

In aquatic habitats of karst regions (carbonate based geological substrate) a phenomenon of calcite deposition may occur. In temperate zones and non-thermal (flowing) waters the deposit that forms is called tufa. It is a porous calcium carbonate deposit that develops in carbonatesupersaturated waters (Chafetz and Folk, 1984), where calcite crystals are deposited on immersed objects including organisms such as algae and mosses and animaloriginating structures (Riding, 1991; Carthew et al., 2003; Matoničkin Kepčija et al., 2006). Tufa deposits occur in karstic regions around the world but there are few studies of leaf litter processing in these habitats (Casas and Gessner, 1999; Carter and Marks, 2007; Compson et al., 2009).

We investigated the relationship between leaf decomposition and tufa deposition. Secondly, we assessed the

\footnotetext{
*Corresponding author: mmilisa@inet.hr
}

effect of flow velocity and season on leaf litter breakdown because these have been confirmed as the most important environmental factors that affect the tufa deposition rates (Zhang et al., 2001; Drysdale et al., 2003).

Increases in phytoplankton abundance in the lakes and vascular vegetation on tufa barriers (lotic region) have been noted over the last decades at the Plitvice Lakes (Špoljar et al., 2007). Previous studies showed that the higher levels of $\mathrm{CO}_{2}$, lowered $\mathrm{pH}$, leached phosphorus and increased organic matter content which may all occur during plant litter decomposition could impede tufa deposition in the system (Golubic and Schneider, 1979; Srdoč et al., 1985; Woodruff et al., 1999; Plant and House, 2002). On the other hand, the microorganisms that colonize leaf litter may provide favorable conditions for calcite crystals nucleation by exuding complex polymers. Additionally, autotrophic (micro)organisms are an important factor because they utilize excess $\mathrm{CO}_{2}$, and hence buffer the $\mathrm{pH}$ change and lower the amounts of $\mathrm{CO}_{2}$ which is a prerequisite for calcite precipitation 


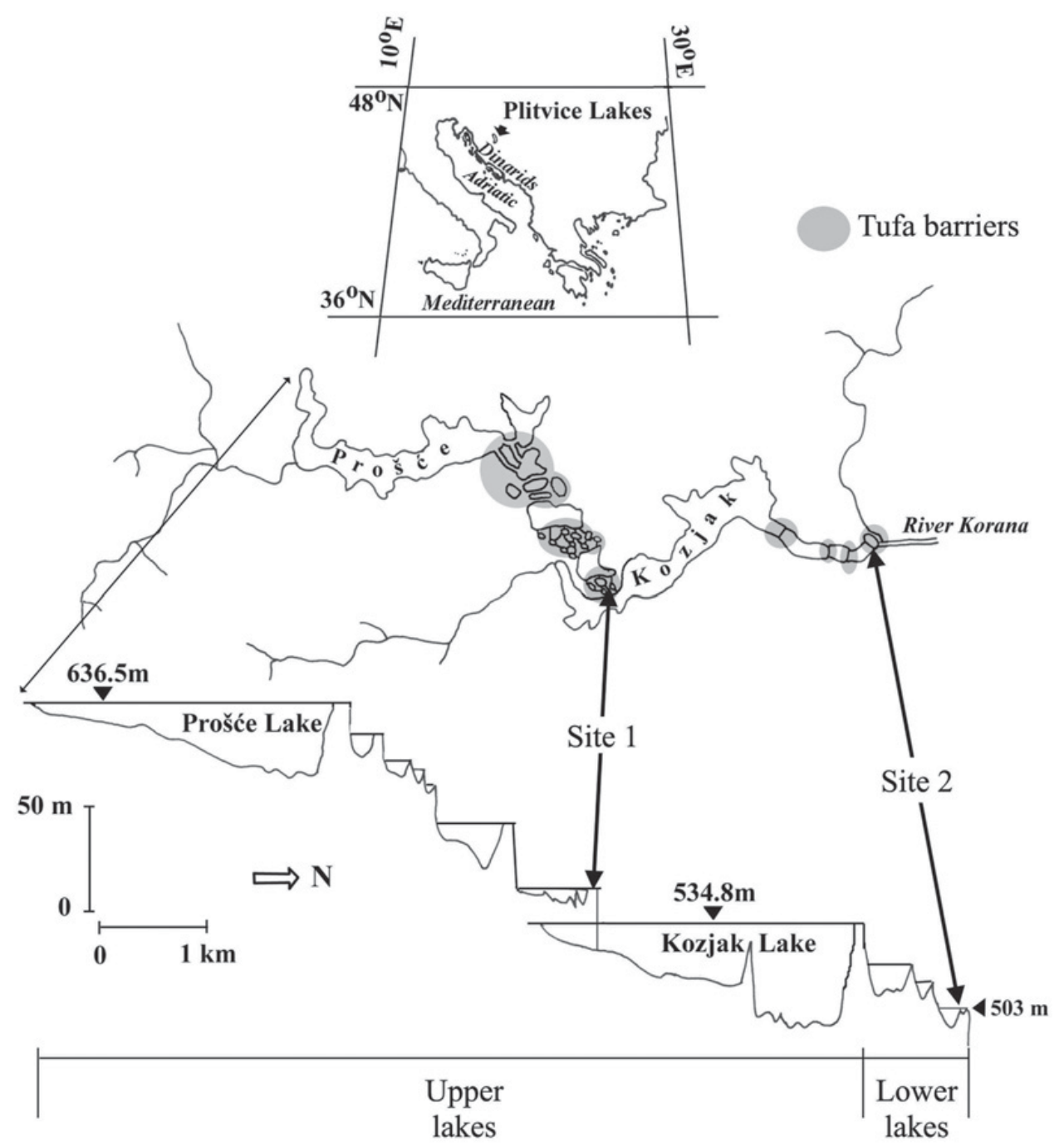

Fig. 1. Plitvice lakes, and the two study barriers.

(Srdoč et al., 1985; Freytet and Verrecchia, 1998; Janssen et al., 1999).

Tufa crust that develops on leaf litter surfaces may slow down the breakdown process, so another concern is the lake filling associated with greater input and persistence of plant material. On the other hand, the growth of crystals may damage leaves, making them more susceptible to breakdown by water flow and microorganisms.

Since the study was done at tufa barriers (flowing water) we hypothesized that the positive effects of rough surfaces of decaying leaves and the attached microorganisms with the excreted polymers prevail over negative effects of metabolic byproducts (flushed downstream by the flow) and that leaf litter breakdown would not retard calcite deposition. Reversely, we expected that calcite crystals would not retard leaf breakdown, especially combined with higher flow velocities and higher temperatures during summer since higher temperatures increase the metabolic rates of microorganisms and faster flow mechanically erodes the leaves.

\section{Methods}

\section{Study site}

The study was carried out at the tufa barriers in the fluvial lakes (barrage-lakes) system of the Plitvice Lakes in Croatia, located in the karst region of NW Dinarids (Fig. 1). The system is composed of 16 oligotrophic lakes with water flowing from one lake to the other over tufa barriers. The system is approximately $8.2 \mathrm{~km}$ long, located at $636-503 \mathrm{~m}$ above sea level and divided into two sections. The upper section is situated in a dolomite valley, whereas the lower section is located in a limestone canyon. Tufa deposition rates (TDR) are substantially lower in the upper section than in the lower section (Srdoč et al., 1985) 
and scarcity of shredder fauna allows for study of abiotic factors on leaf breakdown. One sampling site per section was selected to provide two different TDR for leaf litter breakdown experiments.

\section{Experimental design}

Leaves of two common plant species were used in this experiment: (1) beech (Fagus sylvatica L.), representative of the riparian woody vegetation, and (2) butterbur (Petasites hybridus (L.) P. Gaertn., B. Mey. and Scherb.), representative of the immersed herbaceous vegetation. Beech leaves were collected upon defoliation in autumn and butterbur leaves were cut at the same time. Ten grams of air-dried leaves were packed into $20 \times 30 \mathrm{~cm}$ nylon mesh bags with mesh size $3 \times 11 \mathrm{~mm}$. The bags were mounted on steel bars and attached to the barrier bed in triplicate at four habitats representing combinations of two TDR and two flow velocities. The two flow velocity categories at study sites were $<30 \mathrm{~cm} . \mathrm{s}^{-1}$ and $>60 \mathrm{~cm} . \mathrm{s}^{-1}$. The experiment was conducted during January-February and June-July to assess the seasonal effect on leaf breakdown. The bags were retrieved at weekly intervals over two months. Total number of samples was 3 replicates $\times 2$ sites $\times 2$ flows $\times 8$ weeks $\times 2$ seasons which totals 384 samples yielding 64 (mean of three replicates) data points per leaf species. Samples of beech leaf litter after the fourth week during the summer experiment at high tufa depositing site with fast flow were discarded because several mesh bags were torn and the results were compromised.

\section{Data collection and analyses}

The mesh bags were retrieved by quickly removing them from the barrier bed and placing the entire sample in a plastic container so virtually no tufa was lost. Upon retrieval the mesh bags were transported to the laboratory where the few attached invertebrates were removed. They were discarded as a factor because: (1) in some cases time for achieving total mass loss was shorter than the colonization time for animals; (2) the dramatic change in beech breakdown observed at different flow regimes and TDR combinations suggests that the breakdown process is primarily affected by these abiotic effects; (3) of scarcity of shredder fauna at tufa barrier habitats probably because calcite deposits on leaves diminish the accessibility of this food source (Miliša et al., 2006; Previšić et al., 2007). To obtain total mass, tufa mass, leaf mass and masses of organic and inorganic components, the leaf litter was processed as follows: (1) air-dried and weighed to a precision of $0.1 \mathrm{mg}$, (2) soaked in $15 \% \mathrm{HCl}$ solution to remove deposited tufa until no gas is produced (maximum $15 \mathrm{~s})$ rinsed in distilled water and dry-weighed again, (3) ashed at $500{ }^{\circ} \mathrm{C}$ for $5 \mathrm{~h}$ and dry-weighed again.

Both linear and exponential (Webster and Benfield, 1986) regression models were used to model the dynamic of leaf litter breakdown and persistence times of leaf litter in each habitat. Differences between breakdown rates of the two types of leaf (one-way) and among three studied factors for each species (three-way) were determined by analysis of covariance (time as a covariate).

Linear regression and analysis of covariance were also used to assess whether TDR differed at different environmental settings and to assess whether leaf quality (inorganic-organic matter ratio) changed during exposure.

For the analyses of effect of leaf breakdown on tufa deposition only the data obtained from the high tufa depositing site (Site 2) was used. TDR at the low tufa depositing site (Site 1) was not high enough to be measured confidently, especially taking into account the simultaneous loss of leaf mass. Furthermore, the summerwinter difference in tufa deposition was more apparent at the high tufa depositing site, facilitating seasonal data comparison. Analysis of variance was used to assess whether TDR are different between tough and soft leaves, Mann Whitney U test was used for the analysis of the amounts of tufa deposited during the first week only.

\section{Results}

\section{Leaf breakdown}

Environmental setting for the experiment is given in Table 1. Only significant differences were found for flow velocities between the two hydraulic habitats (at both sites and both seasons), for TDR between the sites (at both seasons), and for temperature between the seasons. These results support the experimental setup since no differences were found in physicochemical characteristics of water among habitats aside the ones that were used as experimental predictors.

The breakdown rates of beech and butterbur leaves were significantly different under all studied environmental settings (ANCOVA $p<0.001$ ). Butterbur leaves, as expected, broke down significantly faster in all habitats. All studied factors (TDR, seasonality and flow velocity) significantly promoted the breakdown of butterbur leaves (Table 2). The positive effects of tufa deposition and flow velocity on beech leaf breakdown were also statistically significant, but the effect of season was not.

The linear model was more suitable in explaining the variance of our data (considering breakdown after discarding the first week of leaching) than the exponential breakdown model $\left(R_{\text {linear }}^{2}=0.77 ; \quad R_{\text {exponential }}^{2}=0.43\right)$. During the first week the same proportion of mass loss was noted regardless of the environmental factors ( $54 \pm 4 \%$ for butterbur and $12 \pm 2 \%$ for beech). However, breakdown rates after the first week differed with respect to the studied factors (Fig. 2).

Using the linear model, the mean persistence time of leaf litter was extrapolated. The resulting mean persistence time was 62 days for butterbur leaves (range 25-132 days) 
Table 1. Physicochemical characteristics of water (mean values are given) at different habitats during the experiment; * marks significant differences between flows at given site, + marks significant differences between sites, \# marks significant differences among seasons, TDR - tufa deposition rate.

\begin{tabular}{|c|c|c|c|c|c|c|c|c|c|c|}
\hline & \multirow{3}{*}{$\begin{array}{c}\text { Season } \\
\text { Site } \\
\text { Flow }\end{array}$} & \multicolumn{4}{|c|}{ Winter } & \multicolumn{4}{|c|}{ Summer } \\
\hline & & & \multicolumn{2}{|c|}{ Upper } & \multicolumn{2}{|c|}{ Lower } & \multicolumn{2}{|c|}{ Upper } & \multicolumn{2}{|c|}{ Lower } \\
\hline & & & Fast & Slow & Fast & Slow & Fast & Slow & Fast & Slow \\
\hline * & Flow velocity & {$\left[\mathrm{m} \cdot \mathrm{s}^{-1}\right]$} & 0.77 & 0.23 & 0.85 & 0.23 & 0.87 & 0.25 & 0.91 & 0.26 \\
\hline+ & TDR & {$\left[\mathrm{g} \cdot \mathrm{g}^{-1} \cdot \mathrm{wk}^{-1}\right]$} & 0.054 & 0.044 & 0.099 & 0.085 & 0.077 & 0.069 & 0.225 & 0.169 \\
\hline \# & Temperature & {$\left[{ }^{\circ} \mathrm{C}\right]$} & \multicolumn{2}{|c|}{5.35} & \multicolumn{2}{|c|}{5.74} & \multicolumn{2}{|c|}{19.20} & \multicolumn{2}{|c|}{19.78} \\
\hline \multirow[t]{6}{*}{ \# } & $\mathrm{O}_{2}$ & {$\left[\mathrm{mg} \mathrm{dm}^{-3}\right]$} & \multicolumn{2}{|c|}{11.74} & \multicolumn{2}{|c|}{11.51} & \multicolumn{2}{|c|}{7.94} & \multicolumn{2}{|c|}{8.10} \\
\hline & $\mathrm{pH}$ & & \multicolumn{2}{|c|}{8.22} & \multicolumn{2}{|c|}{8.52} & \multicolumn{2}{|c|}{8.19} & \multicolumn{2}{|c|}{8.23} \\
\hline & Conductivity & {$\left[\mu \mathrm{S} . \mathrm{cm}^{-1}\right]$} & \multicolumn{2}{|c|}{367} & \multicolumn{2}{|c|}{363} & \multicolumn{2}{|c|}{352} & \multicolumn{2}{|c|}{350} \\
\hline & $\mathrm{NO}_{3}^{+}$ & {$\left[\mathrm{mg} . \mathrm{dm}^{-3}\right]$} & \multicolumn{2}{|c|}{0.49} & \multicolumn{2}{|c|}{0.45} & \multicolumn{2}{|c|}{0.41} & \multicolumn{2}{|c|}{0.43} \\
\hline & $\mathrm{PO}_{4}^{3+}$ & {$\left[\mathrm{mg} \mathrm{dm}^{-3}\right.$ ] } & \multicolumn{2}{|c|}{0.025} & \multicolumn{2}{|c|}{0.022} & \multicolumn{2}{|c|}{0.033} & \multicolumn{2}{|c|}{0.033} \\
\hline & COD & {$\left[\mathrm{mg} . \mathrm{dm}^{-3}\right]$} & \multicolumn{2}{|c|}{0.79} & \multicolumn{2}{|c|}{0.91} & \multicolumn{2}{|c|}{0.79} & \multicolumn{2}{|c|}{0.74} \\
\hline
\end{tabular}

Table 2. Results of 3-way analyses of covariance for effect of flow velocity, tufa deposition rates and season (temperature) on breakdown of beech and butterbur leaves. Df for all treatments is $1 . T D R$ - tufa deposition rate.

\begin{tabular}{lrrrrr}
\hline & \multicolumn{2}{c}{ Beech $(N=60)$} & & \multicolumn{2}{c}{ Butterbur $(N=64)$} \\
\cline { 2 - 3 } \cline { 5 - 6 } & $F$ & $p$ & & \multicolumn{1}{c}{$F$} & $p$ \\
\hline Time & 6.57 & $\mathbf{0 . 0 1 3}$ & & 140.13 & $<\mathbf{0 . 0 0 1}$ \\
Flow & 10.53 & $\mathbf{0 . 0 0 2}$ & & 33.86 & $<\mathbf{0 . 0 0 1}$ \\
TDR & 7.07 & $\mathbf{0 . 0 1 0}$ & & 13.91 & $<\mathbf{0 . 0 0 1}$ \\
Season & 0.02 & 0.885 & & 63.38 & $<\mathbf{0 . 0 0 1}$ \\
$\mathrm{F} \times \mathrm{T}$ & 6.12 & $\mathbf{0 . 0 1 7}$ & & 0.03 & 0.864 \\
$\mathrm{~F} \times \mathrm{S}$ & 1.75 & 0.192 & & $<0.01$ & 0.937 \\
$\mathrm{~T} \times \mathrm{S}$ & 0.74 & 0.394 & & 6.22 & $\mathbf{0 . 0 1 6}$ \\
$\mathrm{F} \times \mathrm{T} \times \mathrm{S}$ & $<0.01$ & 0.969 & & 3.29 & 0.075 \\
\hline
\end{tabular}

and 442 days for beech leaves (range 62-1020 days) (Table 3). Slowest breakdown was associated with winter season and slow flow for both leaf species. For beech, the slowest breakdown was observed at high tufa deposition site. Mean inorganic-organic matter ratio of leaf mass during the experiment was 0.049 for butterbur and 0.078 for beech. The ratios did not change significantly compared to the initial (control) ratio and neither did the values vary significantly over time.

\section{Calcite (tufa) deposition}

Mass ratio of deposited tufa per gram of leaf mass exhibited an increase over the eight weeks (Fig. 3). Linear regression was found to explain data best $\left(R_{\text {overall }}^{2}=0.75\right)$. TDR (mean \pm SD grams of calcite per gram of leaves per week) were significantly ( $p=0.002, N=57$ ) higher on butterbur $\left(0.16 \pm 0.08 \mathrm{~g} . \mathrm{g}^{-1} \cdot \mathrm{wk}^{-1}\right)$ than on beech leaves $\left(0.09 \pm 0.06 \mathrm{~g} \cdot \mathrm{g}^{-1} \cdot \mathrm{wk}^{-1}\right)$.

Overall deposition of calcite was 2.3 times lower during winter than during summer, but a great increase in the amount of deposited tufa was found during the first week of the winter experiment $\left(0.21 \pm 0.09 \mathrm{~g} \cdot \mathrm{g}^{-1} . \mathrm{wk}^{-1}\right)$ followed by mean TDR of $0.06 \pm 0.07 \mathrm{~g} \cdot \mathrm{g}^{-1} \cdot \mathrm{wk}^{-1}$. For comparison, during the summer experiment the TDR in the first week was $0.22 \pm 0.06 \mathrm{~g} \cdot \mathrm{g}^{-1} \cdot \mathrm{wk}^{-1}$ followed by TDR of $0.18 \pm 0.08 \mathrm{~g} . \mathrm{g}^{-1}$. wk ${ }^{-1}$. The amount of deposited tufa during the first week was significantly higher on butterbur than on beech $(p=0.04, N=8)$.

Mean winter TDR were 1.84 times higher on butterbur than on beech leaves $\left(0.11 \pm 0.08 \mathrm{~g} . \mathrm{g}^{-1} . \mathrm{wk}^{-1}\right.$ and $0.06 \pm$ 0.03 g. $\mathrm{g}^{-1} . \mathrm{wk}^{-1}$ respectively; $p=0.054, N=29$ ). During summer TDR on butterbur was 1.55 times higher than on beech $\left(0.21 \pm 0.06 \mathrm{~g} . \mathrm{g}^{-1} . \mathrm{wk}^{-1}\right.$ and $0.14 \pm 0.08 \mathrm{~g} \cdot \mathrm{g}^{-1} . \mathrm{wk}^{-1}$ respectively; $p=0.009, N=28)$.

TDR on butterbur was significantly higher than on beech $\left(0.16 \pm 0.09 \mathrm{~g} \cdot \mathrm{g}^{-1} \cdot \mathrm{wk}^{-1}\right.$ and $0.07 \pm 0.04 \mathrm{~g} \cdot \mathrm{g}^{-1} \cdot \mathrm{wk}^{-1}$ respectively; $p=0.002, N=32$ ). Only at fast flow there were no significant differences between TDR on the two species (TDR (butterbur) $=0.17 \pm 0.09 \mathrm{~g} \cdot \mathrm{g}^{-1} \cdot \mathrm{wk}^{-1}$ and $\left.\mathrm{TDR}_{(\text {beech) }}=0.12 \pm 0.09 \mathrm{~g} \cdot \mathrm{g}^{-1} \cdot \mathrm{wk}^{-1} ; p=0.27, N=25\right)$.

\section{Discussion}

Casas and Gessner (1999) found that the deposited tufa retarded breakdown. The evidence collected in this study aligns with the argument proposed by Carter and Marks (2007) that the reason for different results could be in the quality of deposited tufa. In the study of Casas and Gessner (1999), tufa formed a firm cover on the entire stream bed, while in our study we observed porous tufa deposited at the barriers between the lakes where the flow velocity increases dramatically, causing the waterfall effect (Zhang et al., 2001; Drysdale et al., 2003). This type of tufa probably allows rapid leaching and colonization by microorganisms which are reported to be a significant factor in the breakdown process (Colpaert and van Tichelen, 1996). We observed that slow flow combined with high tufa deposition extends the persistence time of the tough beech leaves. We explain this by a more compact deposit (in comparison with the aforementioned fast-flow tufa), probably similar to that in Rio Vicario (Casas and Gessner, 1999), which forms in slow flow habitats and obstructs both leaching and microbial colonization. 

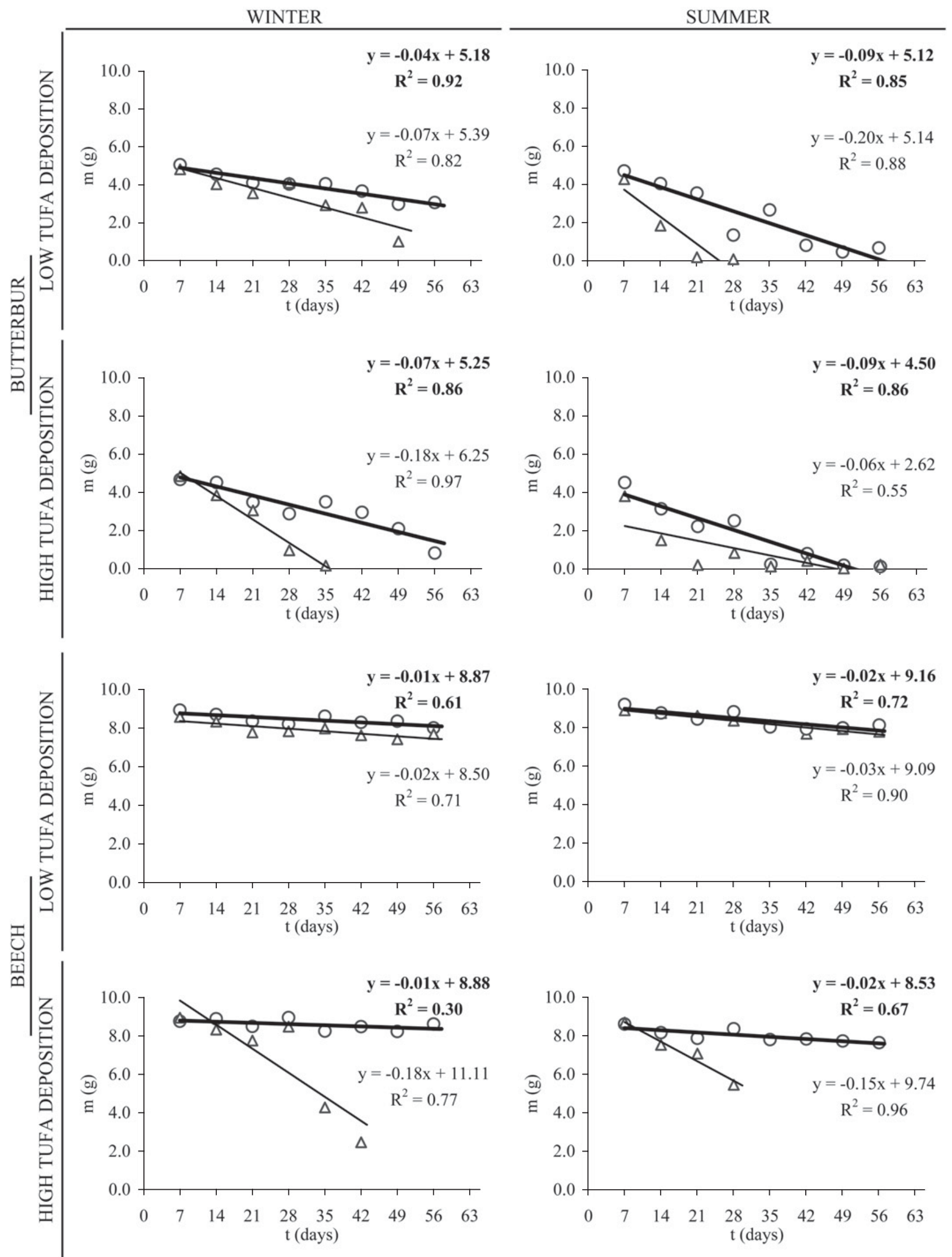

Fig. 2. Breakdown rates of beech and butterbur leaves at high and low tufa depositing sites. Circle-points, thick lines and bold text is for breakdown at slow flow habitats and triangle-points, normal line and normal text is for breakdown at fast flow habitats. 
Table 3. Persistence time in days for beech and butterbur in given environmental conditions. Bold numbers are maxima, bold italic are minima; TDR - tufa deposition rate.

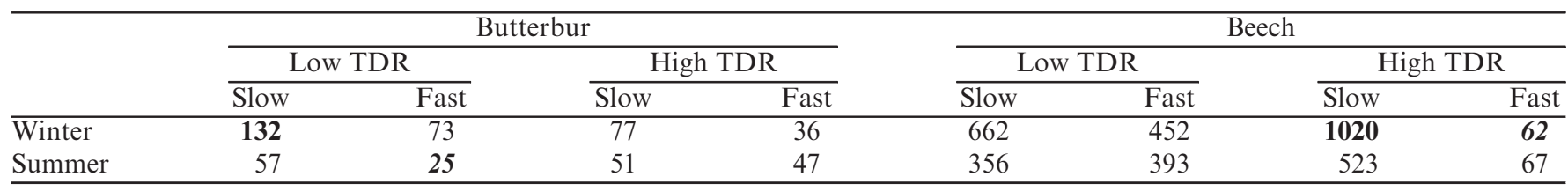

Our results show that the flow velocity is an important factor in leaf litter breakdown. Faster breakdown at high flow is more pronounced at the high tufa deposition sites. The rapidly deposited tufa crystals may physically damage leaves, making them more susceptible to breakdown by the force of water at fast flow. We propose that, in tufa depositing karstic streams, sites with fast flowing water can be regarded as leaf breakdown hot spots (sensu McClain et al., 2003). It should be noted here that this is a site where several bags were torn, however this should not interfere with the previous conclusion. The bags were damaged because of excessive amounts of deposited calcite after five weeks that clogged the mesh and consequently resulted in more resistance to the water current.

Seasonality did not affect the breakdown process as did flow velocity and tufa deposition, enhancing only the breakdown process of the herbaceous species. The cause is probably accelerated microbial metabolic activity at higher temperatures. The lack of a statistically significant seasonal effect on beech leaves can be explained by higher lignin content in beech leaves. Lignin increases leaf toughness and retards microbial colonization and leaf decomposition (Osono and Takeda, 2004; Gonçalves et al., 2007). Significant effects of combined flow and TDR in beech leaf breakdown, and TDR and season in butterbur leaf breakdown further corroborate the thesis that for tough leaves biological degradation is second to the mechanical breakdown, while for soft leaves biological degradation is more important. These results stress the importance of tufa as a factor in plant litter degradation for any kind of leaves.

Since the leaf decomposition starts with leaching which results in great mass loss (Webster and Benfield, 1986; Abelho, 2001), we expected that the leaf litter quality would change in a way that would be observable in the inorganic-organic matter mass ratio. Since this effect was not observed, we concluded that the organic to inorganic matter ratio is not a good indicator of leaf litter quality during breakdown.

The linear model that omits the initial leaf mass proved more suitable in explaining the variance of our data and predicting the persistence time of leaves in water. The exponential model predicts a much longer persistence than we have observed. The exponential model better predicts the breakdown only when fine mesh bags are used (Bedford, 2004; Gulis et al., 2006).

In studies in which coarse mesh bags were used the breakdown rates did not exhibit the ingrained exponential pattern after the first week as well (Casas and Gessner,
1999; Gulis et al., 2006). Coarse mesh allows physical abrasion both by the water itself and by the suspended particles which is important for calcite precipitating habitats.

For the butterbur breakdown no previous studies were found for comparison and mean persistence of beech leaves in our study is in accordance with the beech half life predicted by Webster and Benfield (1986) but the range of persistence times is far greater (62-1020 days), depending on the environmental factors (tufa and flow).

A linear increase in mass of deposited tufa on leaf litter of both fast decaying (butterbur) and slow decaying (beech) litter types indicates that decomposition does not retard tufa deposition. In fact, tufa deposition rates were higher on the faster decaying litter type. Golubic and Schneider (1979) proposed that decomposition processes could increase $\mathrm{CO}_{2}$ pressure and decrease the $\mathrm{pH}$ on a micro scale thus inhibiting tufa deposition and even dissolving calcite. Furthermore, phosphate (leached from the decaying leaf litter) is also known to inhibit the deposition of calcite (Woodruff et al., 1999; Plant and House, 2002). In our study we did not observe any such inhibition. Phosphates may have been evacuated from the solution by colonizing microorganisms (Kock et al., 2006) which additionally produce extracellular polymers that become good places for nucleation of crystals. Moreover, colonized autotrophs utilize the $\mathrm{CO}_{2}$ thus further promoting the calcite deposition.

In contrast with previously observed loss of tufa at Plitvice Lakes during the winter (Srdoč et al., 1985), we found a significant increase in the amount of deposited tufa. The phenomenon was most obvious during the first week of breakdown for the fast decaying species and coincides with the greatest loss of leaf mass. This suggests that tufa deposition is at least indirectly promoted by the decomposition process. Subsequent lower TDR should not discourage this conclusion because TDR did not exhibit a decreasing trend but were rather constant in the remaining weeks of the experiment.

Lower amount of tufa deposited on the tough beech leaves during the first week strengthens the point that tufa deposition is promoted by the decomposition process. Due to the beech leaf toughness, leaching and, consequently, microbial colonization is retarded compared with butterbur. Furthermore, we observed that more tufa was deposited on the beech leaf's underside where the stomata and trichomes are located. These structures enable microbial colonization on tough leaves, and are the starting points of colonization (Canhoto and Graça, 1999). 

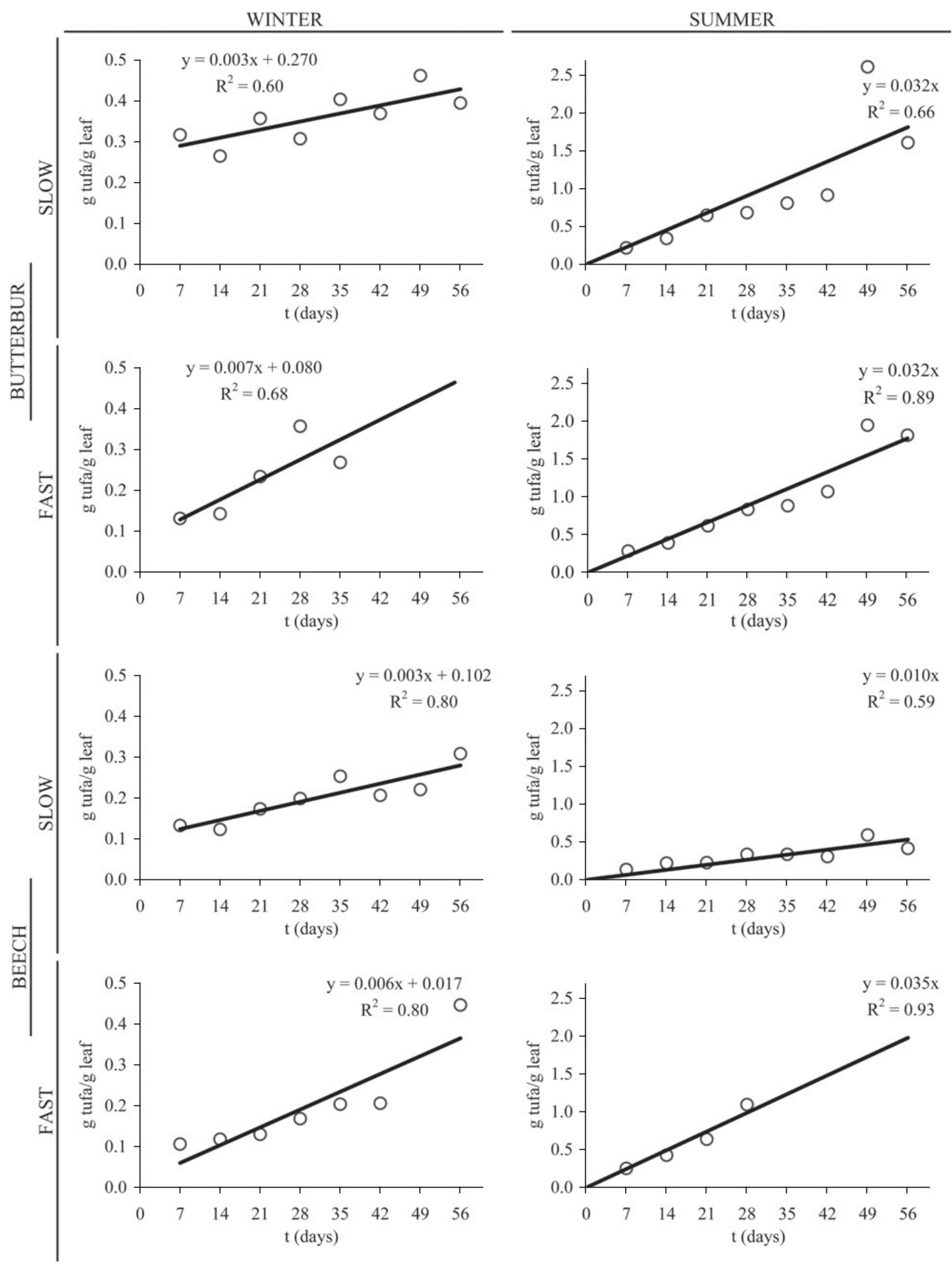

Fig. 3. Tufa deposition rates in summer and winter at habitats with contrasting flow velocity. Note that the $\mathrm{Y}$ scale is smaller for the winter series.

Acknowledgements. This research was supported by the Ministry of Science, Education and Sports of the Republic of Croatia, grant number 119-0000000-1205. We sincerely thank Manuel Graça from the University of Coimbra (Portugal) for all the help and suggestions that improved this paper greatly. 


\section{References}

Abelho M., 2001. From litterfall to breakdown in streams: a review. Sci. World, 1, 656-680.

Bedford A., 2004. A modified litter bag design for use in lentic habitats. Hydrobiologia, 529, 187-193.

Canhoto C. and Graça M.A.S., 1999. Leaf barriers to fungal colonization and shredders (Tipula lateralis) consumption of decomposing Eucalyptus globulus. Microb. Ecol., 37, 163172.

Carter C.D. and Marks J.C., 2007. Influences of travertine dam formation on leaf litter decomposition and algal accrual. Hydrobiologia, 575, 329-341.

Carthew K.D., Drysdale R.N. and Taylor M.P., 2003. Tufa deposits and biological activity, Riversleigh, northwestern Queensland. In: Roach I.C. (ed.), Advances in regolith: Proceedings of the CRC LEME regional regolith symposia, CRC LEME, Bentley, Australia, 55-59.

Casas J.J. and Gessner M.O., 1999. Leaf litter breakdown in a Mediterranean stream characterised by travertine precipitation. Freshwat. Biol., 41, 781-793.

Chafetz H.S. and Folk R.L., 1984. Travertines: depositional morphology and bacterially constructed constituent. J. Sediment. Petrol., 54, 289-316.

Colpaert J.V. and van Tichelen K.K., 1996. Decomposition, nitrogen and phosphorus mineralization from beech leaf litter colonized by ectomycorrhizal or litter-decomposing basidiomycetes. New Phytol., 134, 123-132.

Compson Z.G., Mier M.Z. and Marks J.C., 2009. Effects of travertine and flow on leaf retention in Fossil Creek, Arizona. Hydrobiologia, 630, 187-197.

Drysdale R., Lucas S. and Carthew K., 2003. The influence of diurnal temperatures on the hydrochemistry of a tufadepositing stream. Hydrol. Process., 17, 3421-3441.

Freytet P. and Verrecchia E.P., 1998. Freshwater organisms that build stromatolites: a synopsis of biocrystallization by prokaryotic and eukaryotic algae. Sedimentology, 45, 535-563.

Golubic S. and Schneider J., 1979. Carbonate dissolution. In: Trudinger P.A. and Swaine D.J. (eds.), Biogeochemical cycling of mineral-forming elements, Elsevier Scientific Publishing Co., Amsterdam, 107-129.

Gonçalves J.F. Jr., Graça M.A.S. and Callisto M., 2007. Litter decomposition in a Cerrado savannah stream is retarded by leaf toughness, low dissolved nutrients and a low density of shredders. Freshwat. Biol., 52, 1440-1451.

Gulis V., Ferreira V. and Graça M.A.S., 2006. Stimulation of leaf litter decomposition and associated fungi and invertebrates by moderate eutrophication: implications for stream assessment. Freshwat. Biol., 51, 1655-1669.
Janssen A., Swennen R., Podoor N. and Keppens E., 1999. Biological and diagenetic influence in Recent and fossil tufa deposits from Belgium. Sediment. Geol., 126, 75-95.

Kock C., Meyer A., Spänhoff B. and Meyer E.I., 2006. Tufa deposition in karst streams can enhance the food supply of the grazing caddisfly Melampophylax mucoreus (Limnephilidae). Int. Rev. Hydrobiol., 91, 242-249.

Matoničkin Kepčija R., Habdija I., Primc-Habdija B. and Miliša M., 2006. Simuliid silk pads enhance tufa deposition. Arch. Hydrobiol., 166, 387-409.

McClain M.E., Boyer E.W., Dent C.L., Gergel S.E., Grimm N.B., Groffman P.M., Hart S.C., Harvey J.W., Johnston C.A., Mayorga E., McDowell W.H. and Pinay G., 2003. Biogeochemical hot spots and hot moments at the interface of terrestrial and aquatic ecosystems. Ecosystems, 6, 301-312.

Miliša M., Matoničkin Kepčija R., Radanović I., Ostojić A. and Habdija I., 2006. The impact of aquatic macrophyte (Salix sp. and Cladium mariscus (L.) Pohl.) removal on habitat conditions and macroinvertebrates of tufa barriers (Plitvice Lakes, Croatia). Hydrobiologia, 573, 183-197.

Osono T. and Takeda H., 2004. Accumulation and release of nitrogen and phosphorus in relation to lignin decomposition in leaf litter of 14 tree species in a cool temperate forest. Ecol. Res., 19, 593-602.

Plant L.J. and House W.A., 2002. Precipitation of calcite in the presence of inorganic phosphate. Colloids. Surf. A, 203, 143-153.

Previšić A., Kerovec M. and Kučinić M., 2007. Emergence and composition of trichoptera from karst habitats, Plitvice Lakes region, Croatia. Int. Rev. Hydrobiol., 92, 61-83.

Riding R., 1991. Classification of microbial carbonates. In: Riding R. (ed.), Calcareous algae and stromatolites, Springer-Verlag, Berlin, 21-51.

Srdoč D., Horvatinčić N., Obelić B., Krajcar I. and Sliepčević A., 1985. Calcite deposition processes in karst waters with special emphasis on the Plitvice Lakes, Yugoslavia (in Croatian). Carsus Iugoslaviae, 11, 101-204.

Špoljar M., Primc-Habdija B. and Habdija I., 2007. Transport of seston in the karstic hydrosystem of the Plitvice Lakes (Croatia). Hydrobiologia, 579, 199-209.

Webster J.R. and Benfield E.F., 1986. Vascular plant breakdown in freshwater system. Annu. Rev. Ecol. Syst., 17, 567-594.

Woodruff S.L., House W.A., Callow M.E. and Leadbeater B.S.C., 1999. The effects of a developing biofilm on chemical changes across the sediment-water interface in a freshwater environment. Int. Rev. Hydrobiol., 84, 509-532.

Zhang D.D., Zhang Y., Zhu A. and Chen X., 2001. Physical mechanisms of the waterfall tufa (travertine) formation. J. Sediment. Res., 71, 205-216. 